\title{
EL POSTHUMANISMO Y LOS CAMBIOS EN LA IDENTIDAD HUMANA POSTHUMANISM AND CHANGES IN HUMAN IDENTITY
}

\author{
Gabriela Chavarría Alfaro ${ }^{1}$ \\ prof.gabrielachavarria@gmail.com
}

Fecha de recepción: 9 abril 2014 - Fecha de aceptación: 3 octubre 2014

\section{Resumen}

El siguiente artículo sintetiza los orígenes y los postulados del posthumanismo desde la cibernética a las biotecnologías y analiza los cambios en el concepto de identidad humana, introducidos por esos nuevos paradigmas tecno-científicos.

Palabras clave: cibernética, posthumanismo, biotecnologías y cambios en el concepto de ser humano.

\begin{abstract}
The following article summarizes the origins and postulates of Posthumanism from cybernetics to new biotechnologies and analyses the changes in the concept of human identity, introduced by the new scientific paradigm.

Key Words: Cybernetics, posthumanism, biotechnologies and changes on humane being's concept.
\end{abstract}

El presente artículo pretende introducir críticamente al lector(a) en los postulados del pensamiento posthumanista que empezó a desarrollarse en Occidente a inicios del siglo XXI. Para esto se revisarán primero las transformaciones que ha ido sufriendo la noción de "identidad humana" a partir de dos avances científicos fundamentales del siglo XX: la cibernética y las biotecnologías, puesto que son base del pensamiento posthumanista y posteriormente, se expondrán los postulados de los principales representantes del movimiento, con el fin de adoptar una posición crítica en las conclusiones.

\section{“Identidad humana”, cibernética y biotecnologías}

Al usar el término "identidad humana" se hace referencia a la noción genérica de hombre (en el sentido que engloba lo masculino y lo femenino). Tal como lo explica Edgar Morin (2006):

Se dice justamente los humanos, pues el hombre no aparece sino a través de los hombres y mujeres más diversos, y es a través de ellas y ellos como aparecen, cada vez modulados y desarrollados de forma diferente, los rasgos humanos fundamentales (Morin, 2006, p.70).

El concepto remite entonces a una "identidad humana" común, a través de la cual compartimos el mismo patrimonio hereditario de especie, la misma unidad cerebral como rasgo distintivo notable,

1 Docente e investigadora. 
también la aptitud para hablar un lenguaje de doble articulación, en fin, como concluye Morin "todos los humanos tienen en común los rasgos que hacen la humanidad de la humanidad: una individualidad y una inteligencia de tipo nuevo, una cualidad cerebral que permite la aparición de la mente, la cual permite la aparición de la conciencia" (p.66-67). La manifestación individual particular de esa identidad humana se concreta en la noción de sujeto:

La definición de sujeto debe ser en primer lugar bio-lógica. Es una lógica de autoafirmación del individuo viviente [...] El sujeto comporta nuestra individualidad, un Yo que unifica, integra, absorbe y centraliza cerebral, mental y afectivamente las experiencias de una vida. (Morin, 2006, p.81-82)

Este sujeto es también un agente moral, responsable por sus acciones y una persona, en tanto comporta deberes y derechos en su compromiso con la sociedad en que vive.

Esta noción de sujeto es heredera de la Ilustración y muy particularmente de Rousseau y Kant, quienes pensaron al sujeto como un agente moral que se eleva por encima de su propia naturaleza instintiva gracias a su razón, para crear una comunidad ideal formada por ciudadanos capaces de gobernarse a sí mismos, autónomos, éticos, justos. Además, está en la base de la representación de la "identidad humana" que se encuentra en la Declaración Universal de los Derechos Humanos, donde se habla de la dignidad y el valor de la persona humana y que ha sido consenso para nuestra especie hasta el día de hoy. Es la que está en la base también de los humanismos antropocéntricos del siglo XX. El humano en el centro de toda la creación, en la máxima jerarquía en relación con la naturaleza y las otras criaturas vivas. El principio de Protágoras: "El hombre como medida de todas las cosas". 2

Esa noción de sujeto biológico, autónomo, racional y esencialista como representante de la "identidad humana" va a sufrir cambios importantes en su concepción, a partir de los descubrimientos de: (a) la cibernética y (b) las biotecnologías.

Tanto la cibernética como las biotecnologías son básicas para el pensamiento posthumanista porque sus descubrimientos han permitido a filósofos y científicos imaginar un mundo construido más allá de los postulados humanistas, con seres que traspasan los límites biológicos que son propios de nuestra naturaleza humana. Son ellos los que quieren afirmar radicalmente el fin de lo humano como se ha conocido hasta hoy, para proponer un ser que dirija su propia evolución genética.

A) La cibernética y los cambios en la noción de "identidad humana"

Los teóricos del posthumanismo (Hayles, 1999, Lafontaine, 2000, Cooney, 2003, Peperell, 2007) concuerdan en ubicar el origen del pensamiento posthumanista a partir de la cibernética en las décadas 1950 y 1960 debido a que el desarrollo de la cibernética modificó radicalmente las ideas científicas que se usaban para explicar el mundo y nuestra propia "identidad humana". ${ }^{3}$

2 Esta noción de un sujeto moderno, racional, unitario y totalizante va a ser cuestionada, durante el siglo XX, a través de la teoría feminista y de los filósofos de la posmodernidad como Jacques Derrida, Michel Foucault, Deleuze y Gautarri, entre otros. Sobre la deconstrucción de ese sujeto patriarcal y esencialista desde la filosofía se ha escrito exhaustivamente y no es el propósito de este artículo. Sin embargo, resulta útil citar a Albreth Wellmer (1994) quien distingue tres formas de crítica de la razón y del sujeto que son fundamentales en la crítica postmodernista del racionalismo: 1-la crítica psicológica del sujeto y su razón; la cual se da con el descubrimiento freudiano, 2- la crítica de la razón instrumental como opresión y 3- la crítica por parte de la filosofía del lenguaje al sujeto constituyente del sentido (p. 117-124).

3 Recordemos que la cibernética nace de un trabajo en equipo cuyos primeros representantes son el científico Arturo Rosenblueth y el matemático Norbert Wiener que en su estadía en la Universidad de Harvard encontraron un tema de interés común "la aplicación de las matemáticas y la teoría de la comunicación al método de la fisiología.” De ese trabajo interdisciplinario va a surgir todo un nuevo campo de investigación. (Quintanilla, 2002, p.308-309) 
A partir de la cibernética, se empieza a hablar del ser humano desde la perspectiva de la teoría de los sistemas y del control. El lenguaje lógico-matemático tomó la primacía en la explicación de lo humano, por encima incluso de la perspectiva filosófica y psicológica. Como señala Francisco Varela (1998), los frutos de la cibernética fueron a grosso modo los siguientes:

a-la preferencia por la lógica matemática para entender el funcionamiento del sistema nervioso y el razonamiento humano, b- la "meta" disciplina de las teorías de sistemas que trata de explicar los principios generales que regirían todos los sistemas complejos y c- la teoría de la información que constituye la base de muchas teorías de la comunicación y que se refiere a la comunicación como un principio organizacional y d-los primeros robots y sistemas autoorganizativos (inteligencia artificial). (Varela, 1998, p.34-35)

En este sentido, agrega Varela: "la cibernética constituyó un nuevo paradigma -según la definición de T.S. Kuhn- porque transformó el modo habitual de referirse a un conjunto coherente de ideas científicas que se aceptaban como explicación de un corpus fenomenológico" (Varela, 1998, p.26). En la misma línea de pensamiento, Céline Lafontaine (2000) habla de la cibernética como la fuente de una revolución epistemológica, porque propuso la comunicación como un principio organizacional y el concepto de información llegó a tener una enorme fluidez conceptual, pues se convirtió en un principio universal de organización y regulación. Como afirma Katherine Hayles (1999): "Henceforth, humans were to be seen primarily as information processing entities who are essentially similar to intelligent machines" [De aquí en adelante, los seres humanos iban a ser vistos primordialmente como entidades procesadoras de información quienes son esencialmente similares a máquinas inteligentes] (Hayles, 1999, p.7). ${ }^{4}$

Prácticamente, el concepto de información, según Lafontaine, pasó a sustituir la idea de la vida dentro de la definición del ser, pues se consideró un valor para determinar el lugar que ocupaba un organismo en la jerarquía de los seres. Se empezaron a aplicar modelos de información a animales, máquinas y humanos por igual, como si compartieran el mismo estatus ontológico.

Un buen ejemplo es Gregory Bateson, antropólogo y psiquiatra, quien aplicó la cibernética al estudio de los fenómenos sociales y desarrolló un modelo teórico basado en la interdependencia y la adaptación comunicativa, en la que el individuo aparece claramente como un "ser informacional" completamente permeable por su entorno. Paul Watzlawick llevó a sus extremos esto cuando aplicó los supuestos cibernéticos a las relaciones humanas. Para Watzlawick toda conducta es de naturaleza comunicacional, el individuo se presenta como un ser enteramente determinado por los códigos que utiliza para comunicarse y, por tanto, la posición del sujeto en el sistema social se convierte completamente en su forma de enviar y recibir información. De esta manera, algunos sociólogos como los mencionados, consideran que el estatus ontológico de ser humano se conceptualizó diferente hasta pasar a considerarlo como una pieza más dentro de un engranaje tecnológico, en el que la sociedad ya no es considerada como una sociedad de humanos solamente, sino como una sociedad donde las máquinas inteligentes, los robots, y toda inteligencia artificial deben ser considerados parte similar del entorno social (Lafontaine, 2000).

Los descubrimientos y aplicaciones de la cibernética permitieron despojar a la "identidad humana" (individualizada en ese sujeto racional y autónomo), de singularidad y exclusividad, dentro de un mundo cuyo centro pasó a ser el flujo de información, la teoría de sistemas y no el sujeto. Una de las consecuencias más relevantes del desarrollo de la cibernética es la descorporeización de la razón, pues el razonamiento ya no era exclusivo del cuerpo humano, sino que podía ser reproducido y copiado fuera del cuerpo por cualquier máquina inteligente. La imagen del cerebro como una computadora, que es herencia de la cibernética, muestra con claridad la descorporeización del ser humano, que pasa a estar en una relación horizontal con lo no-humano.

4 De aquí en adelante todas las citas textuales en lengua extranjera son traducción propia, a menos que se indique lo contrario. 
La transferencia de la razón fuera del cuerpo humano (e incluso su superación, pues algunas máquinas pueden superar la racionalidad humana en el procesamiento de datos), es una característica de un mundo donde lo humano convive al mismo nivel con los agentes no humanos y se borran las fronteras entre éstos, pues ambos son valorados por su capacidad de recibir y procesar información. Así, se desmantela el andamiaje filosófico que caracteriza la "identidad humana" como una identidad singular, separada del mundo de los objetos y en posición jerárquica privilegiada dentro de la sociedad. Por tanto, esto trae como consecuencia no solo cambios en la noción de "lo humano", sino reformulaciones del entorno social también, porque ya no estamos frente a un sociedad constituida solamente por seres humanos, sino que los agentes no humanos adquieren cada vez mayor relevancia, y la interacción entre humanos y no humanos transforma nuestras ideas de la vida en sociedad.

Uno de los ejemplos más claros de este cambio en la concepción de la sociedad y lo social es la teoría del actor red del sociólogo de la ciencia Bruno Latour. Esta teoría del actor red expuesta con amplitud en su libro Reassembling the social: An Introduction to Actor-Red-Network (2005), cuestiona y redefine la dimensión social enfrentado dos posiciones; quienes, por un lado, consideran que lo social es homogéneo y, por otro, a quienes lo definen como asociaciones de elementos heterogéneos. Lo social pasa a ser un fluido, una red que conecta y crea asociaciones dentro de las cuales los humanos y los objetos juegan un papel igualmente importante. Esta teoría reflexiona sobre las formas particulares en que los actores (humanos y no humanos) se interrelacionan y median sus acciones. El conocimiento no es algo producido solamente por la mente humana, sino que se encuentra distribuido entre todos los objetos, personas, instrumentos de la red. En este tipo de sociología, lo humano se encuentra valorado simétricamente con lo no humano dentro de lo social. Con esta perspectiva metodológica se ha analizado el funcionamiento de instituciones gubernamentales, servicios de transportes, corporaciones, etc. ${ }^{5}$

Por tanto, descorporeizar la razón fue un logro entusiasta para muchos científicos e informáticos que no cesan de buscar aún hoy la creación cada vez más perfeccionista de la inteligencia artificial, en palabras de Katherine Hayles (1999):

The great dream and promise of information is that it can be free from the material constraints that govern the mortal world. Marvin Minsky precisely expressed this dream when, in a recent lecture, he suggested it will soon be possible to extract human memories from the brain and import them, intact and unchanged, to computer disk.The clear implication is that if we can become the information we have constructed, we can achieve effective immortality. [El gran sueño y promesa de la información es que puede ser liberada de las limitaciones materiales del mundo mortal. Marvin Minsky precisamente expresó este sueño cuando, en una reciente conferencia, sugirió que muy pronto sería posible extraer las memorias humanas del cerebro e importarlas, intactas y sin modificación alguna, a un disco de computadora. La clara implicación es que si podemos convertirnos en la información que hemos construido, podríamos conseguir una efectiva inmortalidad]. (Hayles, 1999, p.13)

Hayles se refiere en el párrafo anterior a las fantasías tecnológicas que siguieron al descorporeizar la razón, pues la información pudo considerarse como algo separado del medio que la portaba: información genética, información que será transferida e implantada en diferentes medios, información que puede viajar libre a través del espacio y el tiempo. La tecnología haciéndose una con la biología humana, base del sueño del pensamiento posthumanista.

5 A la Teoría del Actor-Red se le ha llamado también sociología de lo posthumano y lo postsocial. Además de la bibliografía de sus autores más representativos como Bruno Latour, Michel Callon y John Law, abundan artículos en internet e impresos. Un buen ejemplo es el libro Tecnogénesis (2008) editado por Sánchez Criado, Tomás, Ed. El volumen 1 está dedicado a este tema con artículos como López Gómez, Daniel. Aproximación a la topología de la Teoría del Actor Red, Domínguez Fernando, La cuestión del objeto como cuestión sociológica o Francisco Tirado y Miquel Domenéch Asociaciones heterogéneas y actantes. El giro postsocial de la teoría del actor. 


\section{B) Biotecnologías y cambios en la "identidad humana"}

El segundo paradigma científico que modifica radicalmente nuestra manera de entender la "identidad humana" y es clave para el pensamiento posthumanista es el desarrollo de las biotecnologías.

Según el diccionario crítico de ciencias sociales: La biotecnología es el fruto de los progresos contemporáneos de la biología molecular y la genética. Por tanto, hablar de biotecnología es discernir sobre dos objetos de estudio bien concretos y diferenciados, esto es: 1. Estudio, investigación y aplicaciones derivadas del conocimiento y manipulación en células de origen animal y vegetal, y 2. Estudio, investigación y aplicaciones que se desprenden del conocimiento y manipulación de células de origen humano e incluye tanto la genética aplicada en humanos, como las modernas técnicas reproductivas. (Sánchez Morales, María Rosario. Biotecnología, Diccionario crítico de Ciencias Sociales, http:// www. ucm.es.info/heurotheo/diccionario/B/Biotecnología.htm, 02,01,2013).

Algunos ejemplos de técnicas reproductivas son los bebés probetas, la fecundación post-morten, la maternidad en mujeres de sesenta años, la maternidad en mujeres vírgenes y, en cuanto a genética aplicada, se encuentran el diagnóstico molecular y la terapia génica, entre otras.

Los avances en biotecnología, especialmente después de haber concluido el proyecto del genoma humano, han puesto nuestro metabolismo en un lugar central para nuestra definición de "identidad humana". Vivimos una presión social constante para pensarnos casi exclusivamente como pura corporalidad.

Según Nikolas Rose (2007), a través de la segunda mitad del siglo XX, se ha ido transformando el concepto que teníamos de nosotros como seres humanos con una interioridad compleja y nos hemos ido relacionando con nosotros mismos como individuos "somáticos", es decir, seres cuya individualidad está basada en la carne y la existencia corporal. Son frecuentes en los medios masivos de información, las narrativas sobre enfermedad y sufrimiento, o los discursos populares de dieta y ejercicios. Hay un incremento en la presión social para reconstruir la vida personal a través del actuar sobre el cuerpo. "Exercise, vitamins, tatoos, body piercing, drugs, cosmetic surgery, gender reassignment, organ transplantation: the corporeal existence and vitality of the self has become the privileged site of experiments with the self." [Ejercicio, dietas, vitaminas, tatuajes, drogas, cirugía estética, cambio de sexo, trasplante de órganos; la existencia corporal y la vitalidad del ser se han convertido en el lugar privilegiado de experimentos con el ser] (Rose, 2007, p. 26).

Esa somatización de nuestro ser se ha intensificado desde finales del siglo XX, según Rose (2007), pues si durante los primeros 60 años del siglo XX los seres humanos nos considerábamos habitados por un espacio psicológico interior que debíamos descubrir para entender el origen de nuestros problemas; en las últimas décadas los nuevos descubrimientos de las neurociencias han ido desplazando la terapia psicológica por explicaciones a nivel molecular, a nivel de las neuronas y de los neurotransmisores. Es una visión molecular de la "identidad humana", en la cual el metabolismo pasa a considerarse sinónimo de existencia. Nuestra corporalidad, ahora a nivel molecular, es el blanco de nuestros juicios y nuestras técnicas para mejorarnos a nosotros mismos.

Existe un pensamiento popular de que casi todo puede resolverse con fármacos, la angustia, la tristeza, el mal comportamiento de los niños en las escuelas. Se trata prácticamente de retirarse de una vida humana vivida conscientemente, a una vida que se refugia en el cuerpo y que es una expresión muy primaria de la biología. Pero, además, desde el punto de vista político o más bien biopolítico, esto implica un mayor control hacia los individuos por parte de los Estados o las compañías transnacionales que posean este conocimiento. Hay una tendencia a absolutizar el conocimiento médico y científico frente al cual no queda más que rendirse como ciudadanos, pues como afirma Joseph Dummit (1997) "We don't know how much we don't know about medical truths". [Nosotros no sabemos cuánto es que no sabemos de verdades médicas] (p.93). Por tanto, se asiste a lo que algunos llaman la biologización de la cultura y el gran riesgo de un determinismo genético, que deja en un pasado lejano la noción de ser humano como un agente moral, dueño de sí mismo y su destino. 
Lo anterior puede observarse en el repunte que ha tenido la investigación neurocientífica y la psiquiatría biológica, donde el cerebro orgánico ocupa el centro de la investigación científica sobre el comportamiento humano. A través de test como PET, se ha podido demostrar la base biológica de enfermedades mentales y de comportamientos que se consideran peligrosos para la sociedad. Ahora puede mostrarse el abultamiento o el color en el cerebro que demuestra si una persona es violenta, padece esquizofrenia, etc. Es decir, la mente se ha vuelto visible y la noción de persona se ha biologizado.

Lo que en términos de Foucault (1991) fueron las tecnologías del yo de la antigüedad grecorromana como el dominio interior, el pensamiento vigilante, el autocontrol, las prácticas ascéticas, la búsqueda de la armonía interna "el cuidado de sî" que se refería a la concepción de los seres humanos como seres capaces de mejorarse a sí mismos a través de su conciencia y su razón; han pasado a ocupar un segundo lugar frente a la farmacología. Actualmente se deposita más confianza en el uso (y abuso) de fármacos y medicamentos para que estos hagan los cambios químicos que necesitan nuestros organismos para ser felices o funcionar adecuadamente. Para Giorgio Agamben (2011), esa identidad meramente biológica y asocial implica "el deseo de liberarse del peso de la persona, de la responsabilidad moral y jurídica que ella comporta" (p.71). Pero, para algunos defensores del posthumanismo, el cambio en nuestra noción de "identidad humana" como un ser fundamentalmente neuroquímico es inevitable e irreversible.

\section{El posthumanismo: sus defensores y sus críticos}

El pensamiento posthumanista tiene como base las transformaciones en la noción de "identidad humana" expuestas anteriormente y, además, explora los caminos que esos avances abren para el futuro. Rechaza, por tanto, la idea esencialista del ser humano, al cual pone en posición horizontal con la naturaleza y los agentes no-humanos, en un tipo de convivencia que puede considerarse postsocial como la del Actor Red. Un mundo de humanos, computadores y redes comunicativas, un engranaje tecnológico del cual el humano forma parte igualitaria y no singular.

Robert Pepperell (2003) define así el posthumanismo: "it is the end[...]of the "man-centred" universe or, put less phallocentrically, a "human-centred" universe. In other words, it is about the end of "humanism", that long-held belief in the infallibility of human power and the arrogant belief in our superiority and uniqueness.[ es el fin [...] de un universo 'centrado en el hombre' o para decirlo menos falocéntricamente, un universo 'centrado en lo humano'. En otras palabras, trata sobre el fin del humanismo, de esa creencia largamente sostenida en la infalibilidad del poder humano y en la arrogante creencia en nuestra superioridad y singularidad" (p.171). En otro apartado Pepperell agrega:

[...] technological advances multiply exponentially in the fields of micro-electronics, gene manipulation, and communications and point to the possibility of controlling, synthesising ore ven surpassing aspects of nature which until now have eluded our command.avances [...]los avances tecnológicos se multiplican exponencialmente en los campos de la micro-electrónica, de la manipulación genética y las comunicaciones y nos dan la posibilidad de controlar, sintetizar e incluso traspasar aspectos de la naturaleza que antes de ahora no habíamos podido gobernar. (Pepperell, 2003, 161)

Robert Peperell es un autor que junto con Hans Moravec y Marvin Minsky fundó el movimiento intelectual transhumanista. Este movimiento propone la intervención de la naturaleza humana para llevarla más allá de sus límites biológicos. Consideran que el transhumanismo es un paso necesario para poder llegar a la condición posthumana

Los transhumanistas [...] vemos a la humanidad como un estado transitorio en el desarrollo evolutivo de la inteligencia. Estamos a favor de utilizar la ciencia para acelerar nuestro paso de humano a una condición transhumana o posthumano. Como el físico Freemand Dyson ha dicho: "La humanidad me parece un comienzo magnífico, pero no la palabra final". (Una declaración transhumanista. Consultado El 2 de abril del 2012 en htpp://www.transhumanismo.org) Asociación transhumanista latinoamericana. 
Para los transhumanistas, el hombre posthumano sería ya una persona de unas capacidades físicas, intelectuales y psicológicas sin precedentes, porque ya habrían sobrepasado los límites biológicos, neurológicos y psicológicos. "Posthumans will be persons of unprecedented physical, intellectual and psychological ability, self-programmin and self-defining, potentially inmortal" [Los posthumanos serán personas de habilidades física, intelectuales y psicológicas sin precedentes, autoprogramados, autodefinidos y potencialmente inmortales" (Pepperell, p.170). A la vez, ya no estaría concebido como superior ni singular y conviviría horizontalmente con robots y sería ciborg. ${ }^{6}$. Por ejemplo, durante el siglo XX, el objetivo de los médicos y de la medicina era restaurar nuestra salud a los niveles considerados biológicamente normales. Sin embargo, hoy, el objetivo de la biomedicina no es el estado normal o natural del sujeto, sino traspasar los límites biológicos para llevar a la persona a unos estándares más allá de sus límites naturales, es decir, estándares posthumanos.

Por un lado, los defensores del posthumanismo, como los representantes del transhumanismo no creen que exista ninguna esencia espiritual o alma en el ser humano y reafirman la idea de una "identidad humana" que queda reducida al órgano de su cerebro y a una visión molecular de su cuerpo, es una identidad concebida como pura materialidad. ${ }^{7}$ Un cuerpo cuyas partes externas e internas van adquiriendo un valor en sí mismas y pueden ser, en su mayoría, reemplazadas, injertadas, transformadas. Por otro lado, su interioridad queda reducida a información, códigos genéticos, procesos químicos que pueden ser descifrados y modificados. Asumido así, "la identidad humana" aparece como un espacio de constante modificación y de experimentación. Para ellos, el humanismo es una etapa finalizada, pues el humano ya no se sitúa en el centro ni como medida de todas las cosas, sino en relación con la simbiosis con el mundo tecnológico y biológico. Muy cercano a la noción de simbionte expuesta por Jöel de Rosnay. ${ }^{8}$

Quizás el filósofo del posthumanismo más conocido internacionalmente es el intelectual alemán Peter Sloterdijk, quien a partir de su conferencia titulada "Normas para el parque humano" (Alemania, año 2000) puso en el debate público estas ideas. Sloterdijk es un filósofo muy polémico, considerado por muchos de "ultraderecha" y continuador del sueño del superhombre de Nietzche, además ha sido

6 Según la ciencia popular hay que establecer algunas diferencias entre androide, robot y cyborg: "Androide es el nombre que se le da a un robot antropomorfo, es decir, que tiene forma o apariencia humana, y además imita algunos aspectos de su conducta de manera autónoma. La palabra androide posee un origen etimológico griego, al estar constituido por andro (hombre) y eides (forma). Un robot es una máquina o ingenio electrónico programable, capaz de manipular objetos y realizar operaciones antes reservadas solo a las personas. El robot humanoide es aquel que se limita simplemente a imitar los actos y gestos de un controlador humano, por lo que no es un verdadero androide, propiamente dicho. La palabra cyborg se forma a partir de las palabras inglesas Cyber(netics) organism (organismo cibernético) y se utiliza para designar una criatura medio orgánica y medio mecánica, generalmente con la intención de mejorar las capacidades del organismo utilizando tecnología artificial." Consultado el 13/03/2012 en (http://www.cienciapopular.com/n/Tecnologia/ Androides__Humanoides_y_Cyborgs/Androides__Humano...)

7 Los últimos descubrimientos en neurociencias demuestran la tesis de que conceptos que antes considerábamos inmateriales como el alma pueden situarse en el cerebro. Ver de Punset, El alma está en el cerebro.

8 Joël de Ronsay en su libro El hombre simbionte (1995) expone su pensamiento sobre el tercer milenio y la evolución del humano en fusión y relación simbiótica con su entorno, es decir, no sólo el humano va modificando su entorno sino que va modificándose a sí mismo con él. Ronsay plantea que después del homo sapiens que buscaba dominar las especies con su inteligencia y del homo faber que buscaba usar sus utensilios y herramientas, y después el homo economicus, consumista y depredador, viene ahora el hombre simbiótico que vive en armonía con un ser más grande que él, que él mismo ha ayudado a construir y que a la vez lo construye a él, es una vida híbrida, un super cerebro planetario, el cerebro del cybionte (cerebros humanos, computadoras y redes de comunicación interconectados). Recordemos que el significado de "simbionte" es un ser vivo que vive en asociación con otro, asociación del cual los dos sacan provecho, pero además la simbiosis es una asociación de individuos de diferentes especies. Por tanto, Ronsay no se refiere al hombre del futuro como superhombre, ni biorobot, ni supercomputadora ni megamáquina, sino un hombre simbiótico en estrecha colaboración con el sistema social que ha exteriorizado a partir de su cerebro, sus sentidos y sus músculos. (cfr.p.20-23). 
fuertemente criticado por Jürgen Habermas y polemizado varias veces con él. No obstante, es imposible no mencionarlo al hablar de posthumanismo, pues es quien comenzó el debate y se ha mantenido activamente en este.

Para Sloterdijk (2008), el humanismo tradicional, basado en la cultura del libro y en la ilusión de que un canon de lecturas y unas técnicas pedagógicas podrían civilizar al hombre, ha fracasado. En este siglo de la velocidad, de las tecnologías de la información, de las biotecnologías y la globalización cultural, "la coexistencia humana se ha instaurado sobre fundamentos nuevos. Estos son -como se puede mostrar sin dificultad- decididamente postliterarios, postepistolográficos y en consecuencia (posthumanísticos)" (p.28). Actualmente, la socialización de los humanos está en manos de los medios de información mediática y las nuevas tecnologías. Es el siglo de la velocidad y del cambio de nuestra autorepresentación como especie, por tanto, Sloterdijk pregunta ¿por qué no usar otros medios para promover esa domesticación que tanto se buscó y no se logró con el humanismo letrado? Para él, el uso de las biotecnologías es parte de las antropotécnicas o conjunto de técnicas desarrolladas para modificar el comportamiento humano. Como explica Santiago Castro-Gómez (2013), Sloterdijk retoma el pensamiento del sociólogo y filósofo alemán Arnold Gehlen, quien conceptualiza al hombre como un ser deficitario, al que le faltan los órganos especializados para adaptarse al medio ambiente y, por tanto, la técnica suple, y sustituye los órganos que el humano no tiene, para producir el ambiente artificial que necesita.

La incubadora para el hombre y la humanidad es producida por tecnologías de hardware y su clima determinado por tecnologías de software.[...]Si hay hombre es porque una tecnología lo ha hecho evolucionar a partir de lo pre-humano. Ella es la verdadera productora de seres humanos o el plano sobre el cual puede haberlos. De modo que los seres humanos no se encuentran con nada nuevo cuando se exponen a sí mismos a la subsiguiente creación y manipulación, y no hacen nada perverso si se cambian a sí mismos autotecnológicamente, siempre y cuando tales intervenciones y asistencia ocurran en un nivel suficientemente alto de conocimiento de la naturaleza biológica y social del hombre, y se hagan efectivos como coproducciones auténticas, inteligentes y nuevas en trabajo con el potencial evolutivo. (Sloterdijk, 2006, p.14)

Para Sloterdijk el ser humano ha tenido siempre que autotransformarse para preservar su existencia y es perfectamente lógico que surjan nuevas antropotécnicas. Sus críticos ven en Sloterdijk un defensor de las prácticas eugenésicas, pero otros como el mismo Castro-Gómez (2013) no lo considera así y lee en Sloterdijk a un filósofo que se preocupa por el actuar responsablemente.

Hay algunas posturas que sin llamarse exclusivamente posthumanistas parten de bases similares. Fernando Broncano (2009), por ejemplo, rechaza la creencia de que el hombre sea un ser incompleto y necesite de la técnica para suplir la falta de órganos, porque el ser humano ha evolucionado gracias a las técnicas, prótesis y contextos de artefactos de sus ancestros homínidos: "no necesitan la técnica para completarse, son un producto de la técnica. Son, fueron, somos lo que llamaré seres ciborgs, seres hechos de materiales orgánicos y productos técnicos como el barro, la escritura, el fuego" (Broncano, 2009, p.19-20).

Como puede verse, la noción de prótesis en Broncano es muy amplia, pues habla de prótesis materiales y culturales como sistemas de signos, estas últimas, modifican el pensamiento humano. Además las prótesis ampliativas, también crean funciones vitales. Sin embargo, Broncano reconoce que las prótesis son parte de relaciones y de planes políticos de diferentes sociedades y que debe haber una reflexión ética mayor sobre las posibilidades abiertas por las biotecnologías.

\section{Algunas posturas críticas}

Francis Fukuyama (2002), adopta una posición de resistencia frente a la aplicación de las biotecnologías y propone defender la "identidad humana" expuesta al principio de este artículo y salvaguardar la naturaleza humana cuando dice 
[...] the most significant threat posed by contemporary biotechnology in the possibility that it will alter human natures and thereby move us into a "posthuman" stage of history. This is important I will argue, because human nature exists, is a meaningful concept, and has provided a stable continuity to our experience as a species. [la amenaza más significativa planteada por la biotecnología es la posibilidad de que ella alterará la naturaleza humana y nos llevará a un estado posthumano de la historia. Esto es importante, yo diría, porque la naturaleza humana existe, es un concepto significativo y nos ha proporcionado una continuidad estable a nuestra experiencia como especie]. (Fukuyama, 2002, p.7)

Por consiguiente, este autor es uno de los críticos más reconocidos internacionalmente contra el pensamiento posthumanista, él lo conceptualiza como la más grande amenaza contra los cimientos de la sociedad humana.

Por su parte, Jill Diddur (2003), en su crítica al posthumanismo, establece un interesante paralelismo entre los postulados principales de Sloterdijk y los de la compañía de alimentos transgénicos de Monsanto. Diddur se refiere a que, ya sea la creación de un ciborg o los alimentos transgénicos, los posthumanistas y los defensores de Monsanto insisten en que no se puede separar lo natural de lo artificial, ni en plantas ni en humanos, pues la hibridez y el borramiento de las fronteras entre lo natural y lo artificial es contundente.

Sin embargo, Diddur (2003), argumenta que esto no es cierto en el accionar político y económico de las grandes compañías biomédicas y de alimentos transgénicos, pues los ingenieros genéticos necesitan de una clara distinción entre naturaleza y cultura para poder patentar sus descubrimientos. Por tanto, en la crítica de Diddur, el discurso posthumanista pierde cientificidad y es evaluado como retórica económica y política.

Otra posición crítica, igualmente interesante, es la de Neil Badgminton (2003), que señala que a pesar de que el posthumanismo declara el fin del hombre, (a su vez) hace lo posible por perpetuar al hombre a través de sus modalidades de prácticas científico-tecnológicas y, por tanto, este autor propone entender el posthumanismo como una reescritura lenta y reflexiva del humanismo.

\section{A manera de conclusión}

La mayoría de los teóricos del posthumanismo concuerdan en que el ser

humano es inseparable de la técnica y se modifica a sí mismo en relación con su entorno, en una relación que, a la vez, modifica su "identidad"; sin embargo, hay divergencias en cuanto a la transformación que puede alcanzarse a través de las prácticas científico-tecnológicas, ya que como expone Hans Jonas (1997), el tener poder para hacer algo no implica que haya que hacerlo, y hoy más que nunca se requiere una reflexión sobre nuestra responsabilidad con el futuro, pues las posibilidades de dichas prácticas para transformar nuestro mundo y nuestra especie, nos enfrentan a dilemas éticos que hubieran sido inimaginables en el siglo pasado.

El potencial apocalíptico de la técnica-su capacidad de poner en riesgo la pervivencia de la especie humana, echar a perder su integridad genética, modificarla arbitrariamente o incluso destruir las condiciones de su vida superior sobre la tierra---plantea la cuestión metafísica con la que la ética nunca se había confrontado antes, a saber: si debe haber y por qué una humanidad, por qué ha de conservarse al ser humano como la evolución lo ha hecho, por qué ha de respetarse su herencia genética, incluso por qué debe existir la vida. (Jonas, 1997, p.37)

Las preguntas de Jonas sintetizan perfectamente la preocupación que invade a muchos intelectuales de nuestro siglo y nuestra cultura biotecnologizada. Por un lado, la capacidad de poder realizar transformaciones no realizadas nunca antes sobre la naturaleza humana, vegetal y animal y, por otro lado, el poco conocimiento que se tiene sobre las consecuencias futuras de esas transformaciones. Esa falta de conocimiento sobre las consecuencias hace que los riesgos se maximicen; ante lo cual Jonas aconseja prudencia. Ante la duda sobre las consecuencias de una nueva aplicación, él aconseja que es mejor detenerse. Esta es la misma preocupación que expresa Vandana Shiva (2008), sobre la ignorancia que existe acerca de los efectos de las nuevas tecnologías en la ecología y la salud. "Nuestra época se 
caracteriza más por la ignorancia que por el conocimiento y mantener la ignorancia sobre nuestra ignorancia es un tabú fundamental de la cultura tecnocrática" (Ravetz, 1998, citado por Shiva, (2008,) p.130).

Esa ignorancia sobre los riesgos de un imperativo tecnológico-científico es disfrazada ante la opinión pública con un discurso científico que proclama todo lo contrario, es decir, certezas y éxito. Muchas veces esa proclamación de éxito sirve para que compañías de alimentos transgénicos como Monsanto, o compañías farmacéuticas globales, tengan ganancias económicas extraordinarias. Y sirven también para poder liberarlas de los mecanismos de regulación necesarios.

Asimismo, afirma Vandana Shiva: "La fabricación de sustancias y procedimientos peligrosos va más rápido que las reglamentaciones y el control público.” (Shiva, 2008, p.131)

Por tanto, es necesario que se ejerzan controles y regulaciones a nivel mundial y a nivel local, pero, sin duda, una de las tareas principales de los intelectuales de las ciencias humanas y de las ciencias sociales es luchar porque se cumpla el derecho a la información que tienen los ciudadanos, es decir, luchar por la democratización del conocimiento.

El pensamiento posthumanista debería ser parte del debate público y del debate académico porque sus ideas sobre el futuro de la humanidad promueven cambios radicales a las bases sobre las que está construido nuestro mundo, y porque es el pensamiento que se encuentra muchas veces sustentando la acción de compañías transnacionales, farmacéuticas, institutos de investigación avanzada, laboratorios y asociaciones médicas etc. Además, es parte también del imaginario del futuro de la humanidad que se propaga a través del cine y los medios mediáticos. Sin embargo, en el cotidiano vivir, especialmente de los países menos desarrollados, los movimientos sociales que protestan contra el accionar de muchos gobiernos y de transnacionales, defienden aún un discurso humanista, que lucha por la dignidad de la persona y pretende que se respete y resguarde su herencia genética, su identidad biológica común y se respeten sus derechos humanos.

En este sentido, el posthumanismo pareciera encarnar más bien los deseos de una élite mundial postindustrializada y millonaria que tiene cubiertas sus necesidades humanas tan completamente que ahora puede ponerse a pensar en las diferentes formas para extender su existencia, ya sea con técnicas de crionización o clonación de órganos, etc. Visto así, el pensamiento posthumanista podría ser un instrumento para allanar el camino a la libre colonización del cuerpo humano de unos hombres por otros hombres. Podría también ser el instrumento para crear otro tipo de discriminación, la discriminación genética.

Este conocimiento científico y tecnológico se mantiene como un conocimiento de acceso restringido para la mayoría de la población. La responsabilidad intelectual primordial es poner todo esto en el debate público y hacerlo accesible a las mayorías. Por tanto, se espera que este artículo haya contribuido a introducir uno de los temas más preocupantes hoy en el campo de las ciencias humanas, sociales, naturales y exactas; el pensamiento posthumanista.

\section{Referencias}

Agamben, G. (2011). Desnudez. (Trad. Mercedes Ruvituso).Barcelona: Anagrama.

Broncano, F. (2009). La melancolía del ciborg. Barcelona: Herder Editorial.

Castro-Gómez, S. (2012).Sobre el concepto de antropotécnica en Peter Sloterdijk. Revista de Estudios Sociales, p.63-73.

Cooney, B. (2003). Posthumanity. Thinking Philosophically about the Future. Maryland: The Rowman and Littefield.

Didur, J. (2003).Re-embodying Technoscientific Fantasies: Posthumanism, Genetically Modified Foods and the Colonization of life. Cultural Critique, 53, p. 98-115.

Downey, G. \& Dumit J. (Editors). (1997). Cyborgs \& Citalels. Anthropological Interventions in Emerging Sciencies and Technologies. New Mexico: School of American 
Dumit, J. (1997).A digital image of the category of the person PET Scanning and Objective SelfFashionning. Ciborgs and Citadels. Anthropological interventions in Emerging Sciencies and Technologies. Downey, G. \& Joseph Dumit, J. (Eds) New Mexico, School of American Research Press, p. 83-102

Foucault, M. (1991). Tecnologías del yo. Y otros textos afines. (Trad.Mercedes Allendesalazar). Barcelona: Ediciones Paidós.

Fukuyama, F. (2004). "Transhumanism” Foreign Policy, No.144, p.42-43.

Fukuyama, F. (2002). Our Posthuman Future: Consequences of the Biotechnology Revolution. New York: Picador S.A.

Habermas, J.. (2002). El futuro de la naturaleza humana. ¿Hacia un eugenesia liberal? Barcelona: Ediciones Paidós, Primera edición en español. Traducción R.S.Carbó.

Hayles, K. (1999). How We Became Posthuman. Virtual bodies in Cibernetics, Literature and Informatics. Chicago: University Press.

Jonas, Hans. (1997). Técnica, medicina y ética. (Trad.Carlos Fortea) Barcelona: Ediciones Paidós.

Lafontaine, C. (2000).La cybernétique matrice du posthumanisme. Cités, No.4, p.59-71.

Latour, B. (2005). Reassembling the Social. An Introduction to Actor-Network-Theory. OUP Oxford.

Michellini, J. D. (2010) Dignidad humana en Kant y Habermas. Estudios de Filosofía Práctica e Historia de las Ideas, 12, pp.41-49 Consultado el 10 julio 2013 en http://www.estudiosdefilosofía. com.ar.

Morin, Edgar. (2006). El Método 5. La Humanidad de la Humanidad. La identidad humana. Madrid: Cátedra, sexta edición.

Pepperell, Robert. (2003). The Posthuman Condition. Consciousness beyond the brain. Portland, OR: Intellect Books.

Punset. Eduardo. (2009). El alma está en el cerebro. Madrid: Santillana.

Quintanilla, S.(2002). Arturo Rosenblueth y Norbert Wiener: dos científicos en la historiografía de la educación contemporánea. Revista mexicana de investigación educativa, vol.7. No.15, p.303-329.

Rose, N. (2007).The Politics of Life Itself, Biomedicine, Power, and Subjectivity in the Twenty-First Century. Princenton University Press.

Rosnay, J. (1995). L' homme symbiotique.Paris: Éditions du Seuil.

Sánchez, Criado. T. (Ed) (2008). Tecnogénesis. Vol 1.Madrid: AIBR.

Shiva, V. (2008). Los monocultivos de la mente. (Trad. Ana E. Guyer). Monterrey: Editorial Fineo.

Sloterdijk, P. (2008). Normas para el parque humano. (trad.Teresa Rocha) 5ta edición, España: Siruela.

Sloterdijk, P. (2006). El hombre operable. (Trad. Observaciones filosóficas). Revista Observaciones filosóficas. Consultado el 7 de marzo 2011 en http://www.observacionesfilosoficas.net por el nombre del autor.

Varela, F. (1998). Conocer. Barcelona: Editorial Gedisa.

Wellmer, A. (1988). La dialéctica de la modernidad y la posmodernidad en Modernidad y Posmodernidad (compilador Josep Picó). Madrid: Alianza Editorial. p.103-140. 
